\title{
Imaginarios sociales dominantes. Disputas por el agua del río Atuel en Argentina
}

Dominant social imaginaries. Disputes over the water of the Atuel river in Argentina

\section{ANDREA MARINA D'ATRI*}

Resumen: Desde la teoría de imaginarios sociales, es posible describir imaginarios dominantes en el conflicto por el agua del río Atuel en Argentina, que involucra a dos de sus provincias: Mendoza y La Pampa. El objetivo de este trabajo es analizar, desde una metodología hermenéutica, la relación heteronómica que se establece entre una y otra matriz de significación. Basándonos en fuentes secundarias que recuperan testimonios de los sujetos intervinientes en la disputa socioterritorial, de manera provisoria afirmamos que prevalecen imaginarios dominantes de una "cultura del agua" para el caso de Mendoza y de "despojo" para el caso de La Pampa.

Palabras Claves: Imaginarios sociales, dominantes, agua, Atuel, Argentina.

Abstract: From the theory of social imaginaries, it is possible to describe dominant imaginaries in the conflict over the water of the Atuel River in Argentina, which involves two of its provinces: Mendoza and La Pampa. The objective of this work is to analyze, from a hermeneutical methodology, the heteronomic relationship established between one and another matrix of meaning. Based on secondary sources that retrieve testimonies from the subjects involved in the socio territorial dispute, we provisionally assert the prevalence of dominant imaginaries of a "water culture" for the case of Mendoza and of "dispossession" for the case of La Pampa.

Keywords: Social imaginaries, dominant, water, Atuel, Argentina.

\footnotetext{
* Docente e investigadora del Departamento de Comunicación Social, Facultad de Ciencias Humanas, Universidad Nacional de La Pampa, La Pampa, Argentina. Miembro de la Red Iberoamericana de Investigación en imaginarios y Representaciones. Código ORCID: org/0000-0003-1705-3494 Contacto: andreadatri2012@gmail.com
} 


\section{Introducción}

L uchas o conflictos por el agua dulce están presentes en Argentina. Comunidades de dos de sus 23 provincias protagonizan una contienda de aristas múltiples en una de sus principales cuencas hídricas: la cuenca del Desaguadero - Salado - Chadileuvú Curacó (ver figura 1).

La disputa comenzó hace cien años, en territorios donde La Pampa se une con Mendoza, cuando esta última provincia decide utilizar el agua del Río Atuel -que integra la cuenca mencionada- para abastecimiento y riego a través de la construcción de un dique (El Nihuil, en 1947). La puesta en marcha de la represa hidroeléctrica modifica el modo en que se utilizaba el bien común natural aguas abajo, es decir, en la provincia de La Pampa. Se desarrolla paulatinamente una situación de disputa socioterritorial, que con el correr de los años se judicializa. En 1987, la Corte Suprema de Justicia de la Nación ${ }^{1}$ declara la interprovincialidad del cauce y el uso compartido que debía efectuarse de las aguas, pero, sin embargo, en la actualidad sigue subsistiendo la contienda entre ambas jurisdicciones.

Desde estudios en los que convergen aspectos materiales y simbólicos en el marco de relaciones de poder, nos interrogamos por el entramado subjetivo de la nueva realidad suscitada a partir de la disputa territorial mencionada.

El objeto de estudio de este trabajo procura comprender cómo los distintos sujetos sociales construyen sus imaginarios en torno al conflicto por el agua del Río Atuel, analizando la relación heteronómica que se establece entre los que vislumbramos son imaginarios dominantes o predominantes de este proceso. Este propósito se efectúa en el marco de una investigación mayor que desarrollamos actualmente ${ }^{2}$, en pos de categorizar asimismo imaginarios dominados o alternativos del entramado socioterritorial.

Por el momento, la investigación aludida integra un proceso de varias etapas que unifica dos perspectivas: desde las teorías de la ecología política ${ }^{3}$ se realiza una reconstrucción histórica de conformación de los distintos grupos protagonistas del conflicto, un análisis de la conformación de movimientos sociales y asamblearios y sus estrategias de acción (D'Atri, 2017; D’Atri, 2018), los lenguajes de valoración (Martínez Alier, 2004) y los procesos de judicialización (Merlinsky, 2013) de la disputa, así como las nuevas territorializaciones conformadas (Lopes de Souza, 1995; Haesbaert, 2004). Por

\footnotetext{
${ }^{1}$ Máximo tribunal judicial de la República Argentina.

${ }^{2}$ Integra una tesis en realización, en el marco del Doctorado en Ciencias Sociales de la Universidad de Río Cuarto (Resolución No 060416 UNRC-Argentina).

${ }^{3}$ La Ecología Política es un campo de estudio inter y transdisciplinaria en el que se analizan las relaciones de poder y los problemas de conocimiento en torno a la naturaleza, "en términos de su fabricación social, apropiación y control de ella o partes de ella, por distintos agentes sociopolíticos" (Palacio, 2006, p. 7). Además, esta perspectiva discute aspectos no sólo materiales de ese proceso, sino que también realiza una construcción simbólica o imaginaria.
} 
otro lado, la búsqueda se sustenta en acercarnos a una conceptualización y comprensión -siguiendo a Baeza $(2000 ; 2003)$ - desde la teoría de imaginarios sociales, de esquemas interpretativos de la realidad o matrices de sentido dominantes/predominantes y dominados/alternativos ${ }^{4}$, situándonos en el período actual y en territorio de la provincia de La Pampa.

De forma específica, nos preguntamos de qué modo se articulan las relaciones de poder desde los imaginarios sociales y en procesos de territorialización donde suceden conflictos por el uso y apropiación de la naturaleza. Es decir, cómo se instituyen los imaginarios dominantes de Mendoza y de La Pampa en vínculo con el conflicto por el agua del Río Atuel.

La comprensión desde los imaginarios sociales para este caso, consideramos que podrá brindar nuevos conocimientos y sumarse a investigaciones previas que, de manera particular para la región árida y semiárida donde se sitúan tanto Mendoza como La Pampa y las zonas de disputa en particular, se han desarrollado con acercamientos desde las representaciones sociales, un concepto que no es equivalente al de imaginarios sociales 5 .

A continuación, desarrollaremos los antecedentes en los que se inscribe este trabajo, dando cuenta de las formulaciones teóricas que elegimos para entender los procesos sociales de territorialización y significaciones sociales. Seguidamente, expondremos a través de fuentes secundarias, lo que entendemos por imaginarios dominantes/predominantes de las provincias de Mendoza y de La Pampa y cómo cada uno de ellos expresa matrices de sentido de disputa por el agua. Por último, señalamos algunas reflexiones e interrogantes para futuras indagaciones.

\section{Territorios imaginados}

La mención a los conflictos socioterritoriales alude a tramas de reterritorialización. La conflictividad producto de la apropiación y demás prácticas sobre la naturaleza en diferentes espacios, conduce a tratar de comprender de qué hablamos cuando decimos territorio o, lo que sería más acertado, cuando decimos territorios en plural.

Mirar los territorios y sus abordajes implica pensar en relaciones de poder en vínculo con espacios estructurales/materiales y con sujetos situados en éstos y jugando sus prácticas sociales. El territorio es un "campo de fuerzas" donde existen límites, fronteras y espacios de dominio, es decir que coexisten distintas territorialidades, entendidas como relaciones de poder espacialmente delimitadas (Lopes de Souza, 1995, p. 9).

\footnotetext{
${ }^{4}$ Cabe resaltar que en este artículo no profundizamos en el análisis de estos imaginarios alternativos, dominados o periféricos.

${ }^{5}$ Para ampliar acerca de diferencias y complementariedades de los conceptos y teorizaciones sobre representaciones e imaginarios sociales, ver Baeza (2008), Girola (2012), Pérez (2013) y Aliaga et al. (2018).
} 
El territorio es definido por Raffestin (1993) como la manifestación espacial del poder/poderes que se fundamenta en relaciones sociales entre diferentes actores; relaciones que pueden construir territorio -territorialización- o reconstruir los viejos reterritorialización-. Esas relaciones están determinadas tanto por acciones y estructuras concretas, como por estructuras simbólicas. Por lo tanto, no se puede hablar de territorialidad sino de territorialidades. En ellas, los "procesos de territorialización" se constituyen de las interacciones entre las relaciones sociales por la dominación concreta y simbólica de un espacio (Lopes de Souza, 1995; Haesbaert, 2004). A estas miradas le corresponden aquellas que desde la ecología política puntualizan en las especificidades propias de las disputas por el agua. Recientes estudios explican que en la actualidad la lógica capitalista neoliberal ha naturalizado según un criterio o lógica de mercado al agua y a la naturaleza en general, transformándola en "recursos" y bienes mercantiles (Martín, F. et al, 2010). Asimismo, señalan que a una perspectiva constructivista de la relación tecnología-naturaleza (pensando en la construcción de un "agua moderna" del Estado inversor del siglo XX) se contraponen lecturas decoloniales que permiten develar "la complejidad de los conflictos en torno a los modos de habitar, cuyo entramado expresa ontologías relacionales políticas donde la distinción occidental naturaleza-cultura y su corolario promético, es erosionado" (Cavalli, A., Carroza, T.J., 2018, p. 39), y donde se quiebra el contrato hidrosocial con ese estado en "contexto de radicalización del despojo ocurridos mediante el extractivismo" (Ulloa, A; Romero Toledo, H., 2018, p. 34).

En este sentido, situamos el análisis del conflicto por las aguas del río Atuel en un espacio particular con procesos de territorialización influenciados por la expansión del capital, donde hay reacomodamientos de las estructuras materiales de los espacios basados en la desigualdad, lo cual nos lleva a reflexionar desde una mirada crítica y relacional, por aquello imaginario subjetivo que se integra en esa nueva realidad compleja.

El de los imaginarios sociales es un campo teórico y metodológico en construcción; es relativamente nuevo en el sentido que lleva unas dos décadas intentando una operatividad o aplicabilidad. Por ejemplo, la investigadora argentina radicada en México, Alicia Lindón, sugiere como "asignatura pendiente" en estudios teóricos sobre imaginarios socioterritoriales, el apartarse del análisis sólo de los imaginarios anclados preponderantemente en el nivel de los horizontes de sentido, o las tramas de significados, es decir como una dimensión más o menos estructural de tipo cultural. La autora afirma: "parecería que estos estudios dejan una asignatura pendiente acerca de las formas en las que emerge y se resemantiza cada uno de estos imaginarios en situaciones concretas de la cotidianidad de los diversos sujetos" (Lindón, 2012, p. 73).

Asimismo, ha habido escaso despliegue en casos empíricos vinculados a conflictos ambientales desde la teoría de imaginarios sociales, en particular en el ámbito de la Argentina (Aliaga, Maric y Mendoza, 2018). 
Es el filósofo y psicoanalista griego francés Cornelius Castoriadis (1997) quien en la década de los setenta del siglo XX concibe una noción de institución imaginaria de la sociedad, comprendiendo que ésta conlleva un sistema de interpretación del mundo conformador de su singularidad como tal. Los imaginarios sociales son esquemas interpretativos de la realidad, socialmente legitimados, con manifestación material en tanto discursos, símbolos, actitudes, valoraciones afectivas y conocimientos legitimados; históricamente elaborados y modificables y comprometidos con los grupos hegemónicos (Cegarra, 2012). Por su parte, el español José Luis Pintos (1995) distingue que mientras las ideologías se orientan a legitimar valores establecidos por la sociedad, los imaginarios actúan en el campo de la plausibilidad o comprensión generalizada de la fuerza de esas legitimaciones. En tanto, el investigador chileno Manuel Antonio Baeza (2000) los define como matrices de sentido que hegemónicamente se imponen en la lectura de la vida social. El sujeto simplemente "lo padece" por encima de sus propias experiencias vitales. Esto no quiere decir que los imaginarios sociales sean inmodificables o históricamente permanentes; por el contrario, cada época a través de los grupos sociales construye o resignifica los sentidos que desea socialmente transmitir. De allí que se hable de imaginarios sociales "dominantes" y "dominados"; en esencia, son esquemas interpretativos para el sentido social hegemónicamente impuestos, haciendo plausible la vida cotidiana. Lidia Girola (2012) afirma acerca de esta distinción dominantes/dominados que es preciso incorporar el tema del poder y la dominación, porque como señala el sociólogo chileno, "en todas las sociedades existen intentos de apropiación de los universos simbólicos y de los imaginarios sociales por parte de quienes requieren reproducir desde arriba, desde su posición dominante, la situación de privilegio en que se encuentran. Así, hay que ver el campo de lo simbólico como un espacio de lucha" (Baeza, 2000, p. 29, en Girola, 2012, p. 458).

En tanto matrices de significación, y siguiendo a los autores antes señalados todos especializados en teorizar sobre imaginarios sociales-, decimos que los imaginarios pueden ser mecanismos de legitimación de una forma social de organización y de definición de necesidades y mecanismos de satisfacción, inclusión y exclusión, o pueden generar un cúmulo de necesidades nuevas. Son, por lo tanto, estabilizadores y, al mismo tiempo, creadores y movilizadores de lo simbólico y de las prácticas que de ellos se derivan. De manera que el factor imaginario es cada vez más relevante para la comprensión de la sociedad. Y en la relación entre imaginarios dominantes e imaginarios dominados, es importante comprender que los mismos construyen heteronomía, un término que utiliza Castoriadis (1997), que es similar al de hegemonía en términos de Gramsci (1998) pero que no es equivalente ${ }^{6}$. Para el filósofo griego francés, la

\footnotetext{
${ }^{6}$ Dice al respecto Baeza: "Pienso que la diferencia entre ambos conceptos que sin embargo convergen en el tema central de la dominación, es simplemente una cuestión de perspectiva de análisis: la hegemonía ha de ser vista 'desde arriba', es decir desde el Estado, desde las elites y las clases dominantes que detentan en la práctica el poder, etc.; mientras que la heteronomía debe ser vista 'desde abajo', vale decir desde quienes, como dice C. Castoriadis, llegan a modificar sus estados de voluntad en la aceptación de una determinada dominación" (Baeza, 2003, p. 110).
} 
heteronomía es "el estado en que son dados de una vez por todas los principios, los valores, las leyes, las normas y las significaciones y en que la sociedad, o el individuo según los casos, no tiene ninguna posibilidad de obrar sobre ellos" (Castoriadis, 1986, p. 76). Agrega Baeza, en su Glosario básico de la teoría fenomenológica de imaginarios sociales (2008), que heteronomía es el concepto contrario al de autonomía: "Se trata del sometimiento de la voluntad a la de otros, es decir el fenómeno psíquico que permite la naturalización de los contenidos que esta última impone, en especial mediante el recurso de la violencia simbólica." (Baeza, 2008, p. 519).

Es decir que no hay una imposición de dominación por violencia física sino mediante la intervención de elementos del orden simbólico, ideológico y culturales que llevan a las personas o sujetos a aceptarlos acríticamente. Entonces, la legitimación de un orden instituido socioimaginariamente -aunque no sólo de esa manera-, implica que hay una puja o lucha por la imposición de una cierta visión de mundo sobre otra. De allí que Baeza (2000) señale que:

(...) Todo el cuerpo social asumiría la que hegemónicamente se haya impuesto, aunque eso no dirima la confrontación, sino que minimiza el conflicto hasta tanto no aparezcan nuevas oposiciones tratando de, a través de otros imaginarios, imponerse. (Cegarra, 2012, p. 5-11-12).

Es en este punto, el de las nuevas oposiciones, donde podrían surgir imaginarios alternativos u oponentes a los dominados.

En cuanto a la relación de lo espacial con lo territorial como vínculos que permiten construir identidad, Baeza también se ha ocupado del tema en su libro más reciente ${ }^{7}$. Afirma que desde el punto de vista fenomenológico, es una experiencia primordial de los seres humanos realizar una construcción subjetiva e intersubjetiva de 'lo espacial', por lo cual se trata de pensar que hay un tránsito de lo espacial a lo territorial, "entendiendo precisamente la territorialización como el fenómeno de apropiación simbólica de una porción determinada de espacio, con sus debidas delimitaciones (léase fronteras reconocibles), es decir con un 'dentro' y un 'fuera"' (Baeza, 2015, p. 185-189). La territorialización como tránsito conceptual hacia lo cultural, implica entonces que lo identitario deja de ser solo material para ser a la vez praxis social y que a la vez que es experiencia individual, lo es social y colectiva.

Entonces, junto con las explicaciones emanadas desde la ecología política para la comprensión de los conflictos socioterritoriales, las lecturas nos acercan a una teoría fenomenológica (experiencial) de los imaginarios sociales como prisma para la comprensión de la institución identitaria territorial. Y nuestro esfuerzo es intentar comprender que las subjetividades se instituyen -a través del cambio creativo- pero que también son instituidas -mediante legitimaciones heteronómicas-. Dicho de otro modo,

\footnotetext{
7 Baeza, M.A. (2015). Del espacio al territorio. Imaginarios sociales identitarios, en Hacer mundo. Significaciones imaginario-sociales para construir sociedad / Manuel Antonio Baeza. Santiago: RIL editores, 2015.
} 
las subjetividades son parte intrínseca de la constitución imaginaria de la sociedad, y, por tanto, creadora de realidades sociales. No suceden desde las individualidades -pero también desde ellas- sino colectivamente. Hay una conformación imaginario social del mundo y esta nos estimula a tratar de comprender el modo como se efectúa esa institución social que, además, es instituyente. En consecuencia, imaginarios sociales sobre el agua en territorios pampeanos implica pensar en subjetividades que conforman el proceso conflictivo mismo en sus diferentes aristas, donde se observan prácticas, experiencias y narrativas institucionalizados, con sujetos que participan individual y colectivamente del proceso, situados en tramas de imaginarios dominantes/predominantes y dominados/alternativos o periféricos. Por eso nuestro propósito es reflexionar sobre los imaginarios que juegan en esas relaciones de poder instituidas en el conflicto por el agua de un río interprovincial.

\section{Propuesta Metodológica}

Si diseñáramos un gráfico de categorías de imaginarios sociales del conflicto por el Río Atuel en Argentina, deberíamos dar cuenta que existen en la dimensión territorial, así como en el proceso histórico de constitución política, social, económica y cultural, tres grandes áreas que requerirán una descripción de lo sistémico material/estructural y de lo simbólico: Mendoza, el gobierno Nacional argentino y La Pampa. La pregunta por las tramas de poder que vinculan a las tres, cobra valor por cuanto nos permite caracterizar una situación que se constituye de manera histórica. Pero dado que nuestro objeto de análisis se sitúa de manera deliberada en el espacio pampeano, en este trabajo y en función del espacio que este artículo permite, nos limitamos, por un lado, a exponer de manera descriptiva y mediante el análisis de fuentes secundarias de publicaciones y textos de diverso tipo, lo que enunciamos como imaginario predominante de Mendoza y, por otro lado, para el caso de La Pampa, la metodología cualitativa interpretativa suma, al análisis de las fuentes secundarias, la observación participante de eventos vinculados a la temática (como son actos públicos de diversa índole) y algunas entrevistas abiertas, con el fin también de dimensionar el imaginario predominante.

\section{Juntos en el desierto}

Hay diferencias y hay correlaciones al momento de pensar en las dos provincias de nuestro análisis. La zona que atraviesa el río Atuel por ambas jurisdicciones tiene similitudes geográficas y climáticas, pero en este trabajo enfatizamos que las diferencias en términos de situación económica y social - a partir de la constitución de un orden político gubernamental de trayectorias históricas distintas- muestra las desigualdades a la 
hora de pensar en relevancias socioeconómicas, en un contexto general de país. Veamos algunas características de ambos territorios.

La Pampa nació como provincia el 20 de julio de 1951 según la Ley Nacional No 14.034. Antes, desde el punto de vista jurídico y político, había sido el Territorio Nacional de La Pampa Central (Argentina) creado mediante la Ley Nacional $\mathrm{N}^{\circ} 1.532$ de 1884, al concretarse la denominada "Campaña del desierto" 8 que avanzó sobre los pueblos originarios. Esta característica la hizo depender -entre 1884 y 1951-, en términos de autonomía de gobierno, del poder central de la Nación. En la actualidad, tiene una población total de 343.056 habitantes y una densidad de población -según datos del último censo (INPHyV, 2010)- de 2,2 habitantes por km2, cifra muy inferior a la media del país (10,7 habitantes por kilómetro cuadrado). Ocupa una superficie total de 143.440 km2.

El espacio en el cual situamos nuestro análisis se corresponde con el denominado pastoril -sector occidental u oeste de La Pampa- destacado por la aridez y semiaridez de su ambiente, la presencia de escasas localidades y puestos distribuidos en la zona rural. En él, se distinguen dos subespacios: la depresión fluvial y las mesetas occidentales (Covas, 1998). La primera incluye la zona deprimida, drenada por el sistema del Desaguadero. El río Atuel ("Latuel”, vocablo puelche que significa "Alma de la tierra”), nace en las altas cumbres de la Cordillera de los Andes y corre atravesando las provincias de Mendoza y La Pampa e integra la cuenca Desaguadero-Salado-Chadileuvú-Curacó de las más extensas de Argentina-. El río nace a 3.500 metros de altitud en la cordillera de los Andes y desemboca en el río Desaguadero a 280 metros de altitud; tiene una longitud aproximada de $790 \mathrm{~km}$. y drena en una superficie aproximada a los $39.904 \mathrm{~km} 2$ con un caudal medio es de $35 \mathrm{~m} 3 / \mathrm{s}$.

\footnotetext{
${ }^{8}$ La denominada Campaña o Conquista del Desierto tuvo lugar en la República Argentina entre 1878 y 1884, por la que militares del gobierno nacional y provinciales se hicieron con grandes extensiones de territorios que se encontraban en poder de pueblos originarios mapuche, pampa, ranquel y tehuelche. Se incorporó al control efectivo de la república una amplia zona de la región pampeana y de la Patagonia (Puelmapu según los mapuches). La "campaña" hoy es analizada según diversas posiciones: la oficial como campañas militares, como crimen de lesa humanidad, genocidio de los pueblos originarios o conjunto de expediciones militares contra los indígenas. (Wikipedia.org)
} 


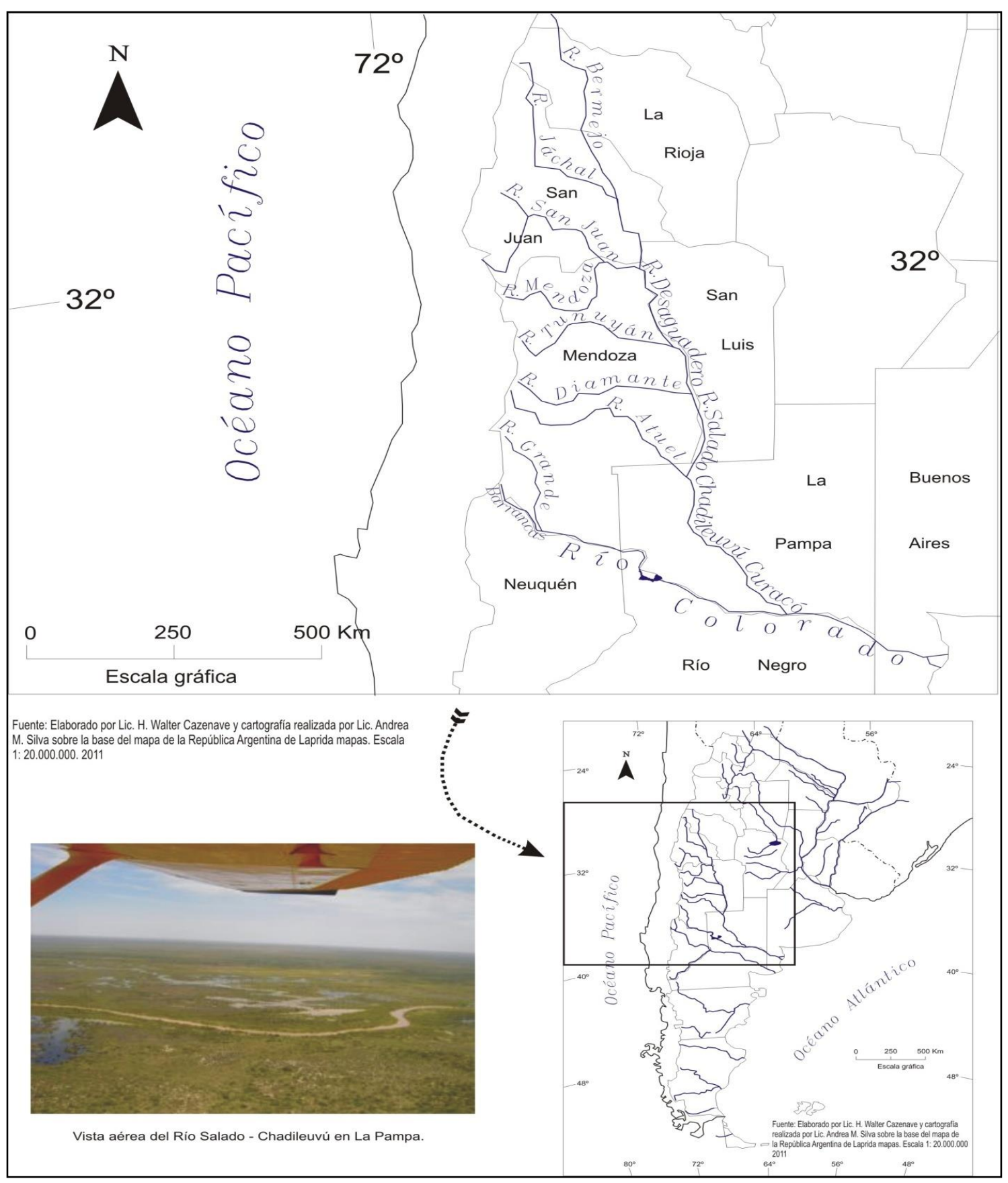

Figura 1: Sistema del Río Colorado. Cuenca Hidrológica del Desaguadero - Salado - Chadileuvú- Curacó en Argentina; subcuenca Río Atuel. (Fuente: Cazenave, 2011, 2015).

En tanto, la provincia de Mendoza se ubica en el centro oeste argentino, al pie de los Andes y en la denominada Diagonal árida sudamericana. Ocupa una superficie de $148.827 \mathrm{~km} 2$. Es la quinta provincia argentina más poblada, con un total de 1.741 .610 habitantes según datos del último censo nacional (Indec, 2010). Su ciudad capital, Mendoza, fue fundada en el año 1561. De clima árido a semiárido y un promedio anual de precipitaciones de alrededor de $200 \mathrm{~mm}$., los aportes hídricos que se utilizan en las 
tierras secas irrigadas, es decir, los oasis, provienen casi en su totalidad de la fusión de las nieves y glaciares ubicados en la Cordillera de los Andes Centrales. Estos ríos de régimen nivo-glacial han definido importantes cuencas que alimentan grandes centros urbanos y superficies bajo riego (Montaña et al., 2005, en Grosso Ceparro; 2014). Los tres oasis de Mendoza (Norte, formado por el río Mendoza, Centro, formado por el río Tunuyán superior y Sur, integrado por el río Diamante y el río Atuel), ocupan sólo el 4,8 $\%$ de la superficie de Mendoza y albergan al 98,5\% del total de la población

Como dijimos, la disputa entre La Pampa y Mendoza por el agua del río Atuel dura ya una centuria, pero se focaliza en un hecho particular: el año 1941, cuando la provincia de Mendoza en convenio con el gobierno de la Nación inicia la construcción del dique El Nihuil (luego Complejo Los Nihuiles). En 1948 la represa es inaugurada por el entonces presidente Juan Domingo Perón y este embalse de las aguas frena los escurrimientos del río aguas abajo, donde el Atuel se unía al Salado en territorio pampeano ${ }^{9}$.

El resultado de la puesta en funcionamiento de la represa El Nihuil fue que en poco tiempo la zona conocida como en territorio pampeano como Bañados del Atuel ${ }^{10}$, pasó a ser un desierto que produjo un éxodo poblacional (Dillon, 2015; Alonso, 2015) y un profundo cambio del ecosistema natural. Es decir que, mientras la decisión de promover el desarrollo en base a riego utilizando la subcuenca del Atuel, consolida para mediados del siglo XX -en Mendoza- "un oasis al sur del territorio que comprende 100.000 hectáreas empadronadas con derecho a riego y una red de $2.530 \mathrm{~km}$. de longitud" (UNLPam, 2011, p. 1) ${ }^{11}$, en la provincia de La Pampa el impacto negativo se mide en aspectos socioproductivos, económicos, demográficos, ambientales y culturales. La geógrafa pampeana Beatriz Dillon señala:

La desertificación alcanza a más de un millón de hectáreas. Desde 1947 a 1970, la regresión fue de 41 por ciento de la población en los departamentos afectados, me refiero a la cuenca ampliada del Atuel. Significa 136 personas por año que tuvieron que irse por año o 3 familias por mes, sumiendo a estas personas en un daño ambiental en muchos casos irreparable. Esto generado por una mega obra de desarrollo en otro estado de Argentina. Cuarenta mil hectáreas de desarrollo contra 1 millón de hectáreas de desertificación. (Beatriz Dillon, testimonio recabado por la autora el 11 de abril de 2018).

\footnotetext{
${ }^{9}$ El río Atuel entraba en La Pampa a través de tres brazos principales, de Este a Oeste: El brazo principal o Atuel Viejo; el Arroyo Butaló, que entraba por unos 200 km. y el Arroyo de la Barda. Había varios brazos menores, de los que los principales eran el arroyo De Las Tinajeras y el arroyo De los Ingenieros. Los años en que se producen "sustracciones de los ríos" a La Pampa son: Río Diamante, en 1808, Atuel Viejo, en 1918; Arroyo Butaló, 1935 y Arroyo de la Barda, 1947 (Gobierno de La Pampa, 1987).

${ }^{10}$ Se trata de un humedal situado entre los brazos de los ríos Atuel y el Río Salado en territorio pampeano, cuya superficie ocupada se estimaba en $3.000 \mathrm{~km} 2$ ó 300 mil hectáreas.

${ }^{11}$ Universidad Nacional de La Pampa Consultora (2005/2011): Estudio para la cuantificación monetaria del daño causado a la provincia de La Pampa por la carencia de un caudal fluvioecológico del Río Atuel, Tomo I y Tomo II. Marcelo Gaviño Novillo: Santa Rosa, La Pampa.
} 
A continuación, ejemplificaremos a través de la recopilación de datos obtenidos, el modo en que consideramos se fue instituyendo imaginarios predominantes que legitimaron una "cultura del agua" para el caso de Mendoza y una lucha ante un "despojo", en el caso de La Pampa, teniendo como objeto de representación material y a la vez simbólico, ese desierto al que para unos había que convertir en oasis, y en el que, para otros, se sumió un territorio húmedo, ahora enajenado de aguas.

\section{"Cultura del agua" o los oasis imaginarios de Mendoza}

El agua en Mendoza es una institución. La primera Ley de Aguas de Argentina se escribió en esa provincia en el año 1884, el mismo año que se daba por finalizada la "Campaña del desierto". El Departamento General de Irrigación (DGI), organismo del gobierno mendocino, ejerce un poder comparable al poder de gobierno central de esa provincial, centralizando la administración del agua de riego, otorgando "derechos de agua" que determinan accesos sectorizados o divergentes. Hemos relevado a los fines del presente trabajo, investigaciones académicas que efectúan un recorrido teórico de comprensión de procesos identitarios de las comunidades del lugar en su vinculación con la problemática del agua. Observamos que a través de ellos es posible enunciar un imaginario de la "cultura del agua" que mediante oasis o vergeles llevarían al "progreso" y al "desarrollo" derrotando el desierto de Mendoza, y esto otorga legitimidad en distintos períodos de la historia provincial en sus procesos institucionales. Al respecto, Saldi, Wagner y Escolar (2014) explican que desde finales del siglo XIX el Estado de Mendoza "impulsó la formación de una identidad local en base a la concentración de recursos en oasis de riego, la producción vitivinícola en gran escala y la inmigración europea." (Saldi et al, 2014, p. 97). Con el agua superficial derivada a oasis de regadío "en detrimento de otras áreas", este proceso se efectuó de esta manera:

(...) Las propiedades privadas en manos de la elite criolla y luego de inmigrantes europeos fueron las que efectivamente obtuvieron derechos de riego, mientras que las tierras ocupadas por poblaciones campesinas e indígenas sufrieron fuertes procesos de desecamiento. Sobre esta base se fortaleció la percepción del territorio y población provinciales como compuesta por dos realidades socio-culturales opuestas e irreductibles, el 'oasis' y el 'desierto'. (Saldi et al, 2014, p. 97).

El análisis de las relaciones entre naturaleza, cultura y conformación de las identidades de la comunidad prevalece en estas investigaciones desde miradas de las teorías sociales críticas. Son las dicotomías las que colaboran en enunciar narrativas, pero también acciones de gobierno y/o políticas concretas que permiten comprender la institución de un imaginario mendocino de la "cultura del agua". Si en términos de conflictividad social -en un principio- este esquema interpretativo o matriz de sentido se 
orienta a legitimar el avance de la civilización sobre la barbarie y el progreso sobre el atraso, los oasis constituirán el avance sobre el desierto y la ciudad agrícola y letrada sobre el desierto atrasado y pastoril, con el fin de volver vitivinícola una provincia ganadera y agrícola, explican Rojas y Wagner (2016). Actualmente, esa impronta se desenvuelve en términos de defensa del "recurso" agua contra el avance de las políticas extractivistas de la naturaleza, como la minería y los hidrocarburos.

Sobre la propia denominación "cultura del agua", la investigadora Lucrecia Wagner (2010) arguye que esta resume el sentimiento de los mendocinos respecto a su relación con el agua. También, que es la expresión utilizada tanto por instituciones mendocinas, en trabajos sobre aspectos legales y ambientales y en testimonios de grupos asamblearios que en las primeras décadas del siglo XXI se manifiestan contra la actividad minera. Luego, cita al investigador Rodríguez Salas, para quien "la cultura mendocina es la cultura ambiental del oasis..." (Rodríguez Salas, 1993, p. 14 en Wagner, 2010) y no está "cultura" no es un proceso coyuntural, sino histórico.

De manera que hacer del "desierto un vergel" (Rodríguez Pardo, 2009, p. 225226), saber "vencer al desierto" y "domar ese medio hostil y moldearlo de acuerdo a sus necesidades" (Montaña et al, 2005, p. 5) expresan sobre la naturaleza una visión que no se corresponde con las características propias del territorio árido, y esa visión permite legitimar unos imaginarios y ciertas políticas sobre el agua. Dice Wagner (2019) que estas nociones llegaron a constituirse en una doxa que influyó en la producción científica local, en políticas estatales y prácticas de gobierno.

Por otra parte, de la literatura científica relevada, interpretamos que la institución de un imaginario dominante que legitima políticas referidas al agua en tanto derechos, usos y apropiaciones es crítica con respecto al statu quo que se instituye material y simbólicamente. Lo es, porque invisibiliza a diversos sectores de la sociedad -por ejemplo, los que no tienen "derecho de aguas" (lo cual implica su privatización) o las poblaciones alejadas de sus oasis-, o porque avala proyectos productivos extractivistas que utilizan grandes cantidades de agua en provecho de sectores mercantiles y en detrimento de usos masivos comunitarios. La crítica es que la naturalización de ciertas políticas avaladas por un imaginario social dominante de "domar la naturaleza" 12 , muestra la contradicción de valerse de la defensa del agua basado en una 'cultura' particular sobre ella que, como contraparte, otorga continuidad a políticas neoliberales

\footnotetext{
${ }^{12}$ De acuerdo a Martín, F. et al (2010), la expresión "domadores de aguas" habría surgido hacia fines de 1880 (con posterioridad a la sanción de la Ley de Aguas de 1884 mendocina -la primera en Argentina-, cuando se trató de convencer al ingeniero César Cipolletti de emprender una serie de obras hidráulicas. El emisario fue Guillermo Villanueva, del gobierno de Tiburcio Benegas (1887-1889), y éste le habría dicho a Cipolletti: "Usted ha domado todas las aguas del mundo, menos las que bajan del techo de América." Posteriormente esta denominación se difundió en distintos medios de comunicación y en la jerga y el imaginario regionales.
} 
que ven a la naturaleza como "recurso" (como es la actividad minera) a ser explotado y, en muchos casos, utilizando ese valioso elemento que dice defender, el cual en última instancia lo hace con fines de ganancia capitalista, en contextos de desigualdad social.

\section{EI despojo: "A los pampeanos nos robaron un río"}

La cita del título de este apartado corresponde al inicio del discurso que el gobernador de la provincia de La Pampa, Carlos Verna (2015-2019), ofreció el 14 de junio de 2017 en una audiencia pública de conciliación ${ }^{13}$ efectuada en la ciudad de Buenos Aires, ante la Corte Suprema de Justicia de la Nación, de la que participaron representantes de los gobiernos pampeanos, mendocino y nacional y a la cual pudimos asistir.

El historiador Fabio Alonso (2015) explica, sobre la acción de regular el río Atuel y no reconocer su interprovincialidad - a pesar del dictamen de la Corte Suprema-, que "el status jurídico de Mendoza, con sus vínculos a nivel nacional y el carácter de territorio nacional de La Pampa (hasta 1951), hizo que fuera imposible establecer alguna regulación a la decisión de cortar el río". Añade que "la apropiación indebida de un curso de agua interprovincial ha desertificado el área central del país, provocando uno de los éxodos más dramáticos y silenciados en la historia argentina" (Alonso; 2015, p. 48-49).

La posición predominante que se ha instituido a lo largo del proceso conflictivo por el río Atuel en la provincia de La Pampa, sugerimos que se corresponde con la de una comunidad que se vio despojada de parte de su territorio, al "arrebatársele" un río. En el análisis de textos poéticos o musicales ${ }^{14} \mathrm{o}$ en la lectura de declaraciones públicas de distintos actores sociales, editoriales periodísticas, discursos emitidos en las movilizaciones de grupos asamblearios que reclaman al gobierno de Mendoza y al Nacional, así como en investigaciones científicas y técnicas, los relatos traslucen una visión que afirma un posicionamiento y sentimiento de pérdida y robo. En particular, se habla de "despojo", de un elemento que se tuvo y ya no; una materialidad sustraída contra la voluntad o a la fuerza. Exponemos a continuación, a modo de ejemplos, algunos testimonios obtenidos del trabajo de campo correspondiente a la investigación en curso y el análisis de algunos de los materiales mencionados. En primer lugar, están los que hablan, sin eufemismos, de la expropiación del bien natural agua:

Nos roban el agua, usan el agua a discreción, con el agua que usan hacen frutales, vinos, conservas, vienen y nos la venden, y no hay nadie que, aunque sea, les

\footnotetext{
${ }^{13} \mathrm{Al}$ momento de finalizar la escritura de este artículo, el juicio que La Pampa iniciara contra Mendoza y el gobierno Nacional en 2014, seguía su curso sin sentencia firme.

${ }^{14}$ En 1987 se publica el primer Cancionero de los Ríos (actualmente hay más y nuevas ediciones), autoría de Rubén R. L. Evangelista y Juan Carlos Pumilla, que compila toda la poesía y música generada sobre los ríos en La Pampa, con especial énfasis en los ríos Atuel y Salado.
} 
cobre un canon (...). (Pobladora de Santa Isabel, localidad limítrofe de La Pampa con Mendoza; testimonio obtenido por la autora en octubre de 2016).

A los pampeanos no nos queda sino batirnos contra la injusticia, porque con el río nos han expropiado la posibilidad de desarrollo y progreso, dejándonos un legado de sequía. (Discurso del presidente de la Asamblea Permanente por los Ríos Pampeanos, audio obtenido por la autora en marzo de 2017).

Por eso vengo acá a exponer (...), fui creciendo y sigo viviendo en esa zona, porque fui uno que pensé que tenía que seguir estando de alguna manera. Algunos me querían despojar, pero nunca le acepté a nadie porque había que estar, porque es nuestro lugar, es nuestra tierra y es nuestra có, es nuestra tierra y es nuestra agua que Guenechén nos dio. (Lonko Che de la Nación Rankulche de La Pampa, en Audiencia Pública ante la Corte Suprema de Justicia de la Nación, 14 de junio de 2017. Versión magnetofónica)

El robo, la pérdida y el despojo no son sólo términos del período que estudiamos (la actualidad); los mismos pueden rastrearse en reclamos individuales y colectivos o expresiones de diversa índole, más atrás en el tiempo. La primera asamblea multitudinaria que inicia un movimiento social de reclamo por los ríos, en el año 1973, se llamó COPDRIP (Comisión Popular en Defensa de los Ríos Pampeanos). El historiador Norberto Asquini expone cómo fue su conformación:

El 11 de abril a la tarde, los presentes organizaron un movimiento dispuesto a desarrollar una acción permanente contra los despojos perpetrados al patrimonio pampeano, y a lograr el reconocimiento de esos derechos (Asquini, 2005, p. 104).

En la revisión de documentos de la mencionada Comisión efectuada en el marco de esta investigación, leemos que una de las primeras acciones que efectúan sus miembros es enviar un telegrama al entonces presidente de la Nación Argentina, Alejandro A. Lanusse, cuyo texto expresa: "Exigimos inmediato cumplimiento decreto 1560/73. La Pampa no permitirá un nuevo despojo" (D’Atri, 2017, p. 7). La construcción del significado de esta expresión es histórica, por más que en la actualidad y en el contexto de políticas neoliberales y extractivistas, se lean desde esa perspectiva.

Una de las instituciones sociales que se funda en 1984 como organización no gubernamental en defensa del agua en La Pampa y que aún cumple una función de gran protagonismo es la Fundación Chadileuvú (FUCHAD). Uno de sus integrantes afirma: “(... ) la defensa del patrimonio se refiere al patrimonio natural del cual La Pampa ha sido reiteradamente despojada y/o agredida. El caso del Atuel es emblemático." (Bassa, 2016: 85). En tanto, el presidente de la entidad, durante un acto público por la celebración del Día del Agua en Santa Rosa (22 de marzo de 2017), expresa:

Solamente 1,5 por ciento de la población de La Pampa vive en lo que fue la orilla de los ríos robados, me refiero por supuesto al Río Atuel y al río Salado Chadileuvú Curacó (...). (audio obtenido por la autora en marzo de 2017). 
Por otra parte, del relevamiento de numerosas publicaciones técnicas, académicas y literarias, destacamos a modo de ejemplo algunos de los títulos cuyas denominaciones reiteran la valoración de la sustracción del bien común por parte de Mendoza y un posicionamiento de reclamo, la nostalgia por una situación que ya no existe y más allá del lamento, la esperanza. A saber: Despojos, históricos y recientes, en el Oeste pampeano (Dillon y Comerci; 2015); El caso del río Atuel desde la perspectiva de los derechos humanos (Scovenna, 2012); Interprovincialidad del Río Atuel (Álvarez Bustos, 1984); El río Atuel también es pampeano (Gobierno de La Pampa; 1979); Testimonios de los ríos robados (Fuchad, 2018); Esperanza. El Lamento del Atuel (Campanari, 2018); Nostalgias de un río (Ugalde, 2018); Zamba del Río Robado (Manuel J. Castilla, 1959), canción emblema que es interpretada en La Pampa en actos públicos por los grupos asamblearios y coros y orquestas dependientes del gobierno provincial. Además, Pequeñas elegías al canto del agua (2012); Atuel, la memoria del agua (Valeria Tochi, documental, 2014); El río Atuel y la lucha pampeana (Gobierno de La Pampa, documental, 2017).

Aquel oeste de los Bañados del Atuel que conformaba un vergel natural en La Pampa, es arrebatado y transformado en desierto. Un imaginario predominante traducido en discursos, movilizaciones, acciones jurídicas, es decir, repertorios que contribuyen a la conformación misma del conflicto, se sostiene en la proclama de lo perdido. Es una comunidad la que se expresa porque lo hace a lo largo de todo el trayecto que comprende la disputa desde el momento en que esta se institucionaliza -con diversas acciones y en diferentes períodos históricos-, y con mayor o menor énfasis según si las estrategias de acción unifican o separan las políticas de Estado (por ejemplo, los juicios), con las del resto de la sociedad (por ejemplo, las movilizaciones asamblearias) (D'Atri, 2018). El grupo social asambleario es un protagonista del conflicto y también, como hemos visto en los discursos de sus miembros, sobresale una adhesión a un imaginario de "despojo".

Un extracto del discurso del gobernador de La Pampa, Carlos Verna (del Partido Justicialista o Peronista), al momento de hablar en la audiencia pública convocada por la Corte Suprema de Justicia de la Nación y que titula este apartado, constituye un ejemplo de lo que representa un discurso interesado (político) en búsqueda de legitimación, el cual sostiene el imaginario predominante pampeano. Este, tensiona, a su vez, con ese otro imaginario dominante mayor mendocino, el de la "cultura del agua":

Señores jueces, para mi Provincia esto es una cuestión de Estado (...), porque esta situación excede ampliamente una gestión de Gobierno. Vengo sin resquemor alguno, vengo con motivación y con fe a afirmarle a este excelentísimo Tribunal que a La Pampa le robaron un río, le robaron el río Atuel... (...) Y yendo puntualmente a lo que hoy nos convoca, queda claro que, a los pampeanos, además de territorio, nos quitaron un río en lo que ha significado el despojo que ocasionó una catástrofe ambiental, además del profundísimo daño social, productivo y emocional que sufrieron los pobladores del Oeste pampeano. (Gobernador de la provincia de La Pampa, Audiencia Pública en la CSJN, 14 de junio de 2017; versión magnetofónica). 
Lo que podemos afirmar -de manera provisoria- es que este imaginario de la desposesión o del despojo ha sido el que ha predominado en la sociedad pampeana, dando legitimidad a las estrategias de acción instituidas en el orden social buscado de parte de los grupos hegemónicos o, en términos de la teoría de imaginarios sociales, heteronomizando la significación que una comunidad ha otorgado a la disputa por el agua. El despojo como término enunciado y con su significación histórica - producido a partir de una política capitalista, neoliberal, de un Estado cuya política de inversión "moderna" ve al bien natural agua como "recurso" a ser explotado-, se despliega e institucionaliza y se manifiesta conformando esquemas de sentido que instituyen una visión dominante o un imaginario social predominante. El pampeano encuentra en el despojo, la expropiación y el robo, sus motivos para dar batalla en la lucha por este bien común, y lo hace socioimaginariamente en esos términos.

\section{Reflexiones finales}

Creemos que la caracterización de imaginarios dominantes, predominantes o de mayor poder heteronómico en el conflicto socioterritorial por las aguas del Río Atuel, ayuda a comprender las formas no solo de mirar la disputa misma, sino de pensar cómo estas institucionalidades van llevando adelante, al modo de un continuum, las transformaciones que pudieran sucederse -sin pensar en evolución, pero sí en cambios- en el mismo proceso; un proceso conflictivo que conforman sujetos cuyas prácticas y experiencias dan marco u objetivan un trayecto histórico desde materialidades, pero también mediante significaciones simbólicas.

La evidente heteronomía que el imaginario de la "cultura del agua" mendocina articula por sobre la del robo o "despojo" pampeano, creemos que se sostiene no sólo en relaciones de fuerza concretas - medida en términos poblacionales, económicos, de gobernabilidad, etc.- que detenta una provincia sobre la otra. Esa fuerza, además, va a la par de un imaginario predominante de progreso y desarrollo productivista que sigue imperando en el actual sistema capitalista neoliberal. Un imaginario materializado en políticas públicas, por supuesto, de las cuales se hace eco Mendoza, pero paradójicamente también La Pampa en el contexto general de sus propias acciones de "desarrollo" -un aspecto para profundizar en futuros análisis-.

Es dable pensar que en toda relación heteronómica, si hallamos imaginarios dominantes, hallaremos imaginarios dominados, alternativos o periféricos. Trabajos de investigadores e investigadoras desde la geografía crítica para el tema del río Atuel en La Pampa mencionan una pérdida de "memoria hídrica" (Dillon y Comerci, 2015). En esta línea, y sin perder de vista que esta investigación se encuentra aún en etapa de elaboración, dejamos abierto el interrogante acerca de subjetividades posicionadas -en la provincia de La Pampa- desde un "olvido" de una forma de vida en un espacio cuyas características 
fueron modificadas por la interrupción de un río. Testimonios de los y las pobladores que permanecieron en la zona ribereña y fueron afectados por la falta de agua, readaptados a nuevas condiciones de vida, dan cuenta de ello.

Como señalamos anteriormente, hacer parecer natural una visión de mundo que en definitiva no ha hecho otra cosa que hacer plausible un cierto orden social (Baeza, 2000) desde unos imaginarios dominantes que se sostienen de manera heteronómica sobre sus alternativos, es parte de la homologación que la sociedad requiere para lograr esa estabilidad. Ese orden se precisa para minimizar las situaciones conflictivas como las que hemos expuesto, y por eso, lo dominante logra su legitimación hasta tanto no aparezcan otros con la suficiente fuerza para desestabilizarlo en su poder. Si bien esta afirmación pareciera ser muy taxativa, no está en nuestra intención que lo sea. Sabemos que entre medio de los extremos perviven grises (procesos, paradigmas, sucesos, modos de ver) que nos permitirían trazar un abanico de imaginarios sociales sobre el tema que nos ocupa. Estos, los vamos desplegando en futuros y más profundos estudios. 


\section{Referencias}

Aliaga, F., Maric, M y Mendoza, C. (2018). Imaginarios y representaciones sociales: Estado de la investigación en Iberoamérica. Bogotá: Universidad de Santo Tomás.

Aliaga, F., y Pintos, J. L. (2012). Introducción: La investigación en torno a los imaginarios sociales. Un horizonte abierto a las posibilidades. Santiago de Compostela: RIPS. Revista de Investigaciones Políticas y Sociológicas, 11(2), 1117.

Alonso, F. (2015). El peronismo en La Pampa. Conformación partidaria y construcción estatal 1945-1955. Buenos Aires: Prohistoria Ediciones.

Álvarez Bustos, P. (1984). Interprovincialidad del Río Atuel. Madrid: Ediciones Depalma.

Argentina, Instituto Nacional de Estadísticas y Censos. (2010). Censo nacional de población, hogares y viviendas 2010. San José: Instituto Nacional de Estadísticas y Censos.

Asquini, N. G. (2005). Crónicas del fuego. Luchas populares, peronismo y militancia revolucionaria en La Pampa de los '70. La Pampa: Amerindia.

Baeza, M. A. (2000). Los caminos invisibles de la realidad social. Ensayo de sociología profunda sobre los imaginarios sociales. Santiago: Red Internacional del Libro.

Baeza, M. A. (2003). Imaginarios sociales. Apuntes para la discusión teórica y metodológica. Concepción: Editorial Universidad de Concepción.

Baeza, M. A. (2008). Mundo real, mundo imaginario social. Teoría y práctica de sociología profunda. Santiago: Red Internacional del Libro.

Baeza, M. A. (2015) Hacer Mundo. Significaciones imaginario-sociales para constituir sociedad. Santiago: RIL Editores.

Bassa, D. (2016). La "pampeanidad" en debate: discursos y prácticas sobre la identidad provincial. La Pampa: EdUNLPam.

Campanari, O. (2018). Esperanza. El lamento del Atuel. Cuentos y relatos pampeanos. Santa Rosa: 7 Sellos Editorial.

Cavalli, A.; Carroza, T. J. (2018). Dicotomía naturaleza-tecnología: diálogo entre el constructivismo social de la tecnología y la ecología política latinoamericana. Pelotas: Revista Novos Rumos Sociológicos, 6(10).

Castoriadis, C. (1983 1ra Edición; 1997, 2007). La institución imaginaria de la sociedad 1. Marxismo y teoría revolucionaria. Barcelona: Tusquets. 
Castoriadis, C. (1986, 4ta. Reimpresión 2005). Los dominios del hombre. Las encrucijadas del laberinto. Barcelona: Gesidsa.

Cazenave, W. (2015). La cuenca del río Desaguadero. Un caso de desertificación por acción antrópica. São Luís: InterEspaco, 1(2), 225-236.

Cegarra, J. (2012). Fundamentos teórico epistemológicos de los imaginarios sociales. Santiago: Cinta de Moebio, 43, 1-13.

Comerci, M. E. y Dillon, B. (2015). Cambios en los modos de vida e impactos sociales en la depresión fluvial Atuel-Salado-Chadileuvú-Curacó. En: Dillon, B. \& Comerci, M. E. (Comp.) (2015). Territorialidades en tensión en el oeste de La Pampa. Sujetos, modelos y conflictos. La Pampa: EdUNLPam.

Covas, M. R. (1998). Los espacios socioeconómicos de la provincia de La Pampa. Huellas, La Pampa: EdUNLPam.

D’Atri, A. (2017). El "fuera de cuadro" de la protesta popular por el Atuel. La Pampa: Anuario, Facultad de Ciencias Humanas, Universidad Nacional de La Pampa, EdUNLPam, 13, 1-16.

D’Atri, A. (2018). Movimientos sociales por los ríos en La Pampa. Estrategias en espacio de borde. María Eugenia Comerci (comp.). La Pampa: EdUNLPam, 163-194.

Fundación Ch. (2018). Testimonios de los ríos robados. La Pampa: FUCHAD.

Girola, L. (2012). Representaciones e imaginarios sociales. Tendencias recientes en la investigación. En: De la Garza, E.; Leyva, G. (coords.) (2012). Ciudad de México: Tratado de metodología de las ciencias sociales: perspectivas actuales.

Grosso Cepparo, M. V. (2014). La escasez hídrica en tierras secas. Un estudio territorial sobre la apropiación, gestión y uso del agua en la cuenca del Río Mendoza (Tesis doctoral). Buenos Aires: FILO, Universidad de Buenos Aires.

Gobierno de La Pampa (1987). El río Atuel también es pampeano. Fiscalía de Estado, Gobierno de La Pampa.

Harvey, D. (2004). El nuevo imperialismo. Sobre reajustes temporoespaciales y acumulación mediante desposesión. Madrid: Revista Viento Sur, 447, 1-26.

Haesbaert, R. (2004). O mito da desterritorializacao. Rio de Janeiro: Bertrand Brasil. Traducción Aichino Lucia.

Lindon, A. y Hiernaux, D. (2012). Geografías de lo imaginario. Barcelona: Anthropos Editorial.

Martín, F., Rojas, F. y Saldi, L. (2010). Domar el agua para gobernar. Concepciones socio-políticas sobre la naturaleza y la sociedad en contextos de consolidación del Estado provincial mendocino hacia finales del siglo XIX y principios del XX. Buenos Aires: Anuario del Centro de Estudios Históricos "Prof. Carlos S. A. Segreti”, 10(10), 159-186. 
Martín, F. y Wagner, L. (2013). Agua o minería. Determinaciones y movilizaciones en la construcción pública del conflicto ambiental en Mendoza. Buenos Aires: Cartografias del conflicto ambiental en Argentina (Gabriela Merlinsky comp.), 287-318.

Martínez Allier, J. (2004). Conflictos ecológicos y lenguajes de valoración. El ecologismo de los pobres: Conflictos ambientales y lenguajes de valoración. Barcelona: Icaria/FLACSO.

Massolo, Néstor. (2012). Pequeñas elegías al canto del agua. La Pampa: Ediciones Amerindia.

Merlinsky, G. (2013). Cartografías del conflicto ambiental en Argentina. Buenos Aires: Ediciones Ciccus.

Montaña, E. et al. (2005). Los espacios invisibles. Subordinación, marginalidad y exclusión de los territorios no irrigados en las tierras secas de Mendoza, Argentina. Sonora: Revista Región y Sociedad, 17(332), 1-32.

Rojas, F. y Wagner, L. (2016). Conflicto por la apropiación del río Atuel entre Mendoza y La Pampa (Argentina). Anápolis: HALAC VI, 2, 278-297.

Saldi, L., Wagner, L. y Escolar, D. (2014). Discursos de lo social en problemáticas ambientales: agua y minería en el centro-oeste argentino. Chiapas: Ambiente \& Sociedad, 18(1), 97-114.

Pumilla, J. y Evangelista, R. (2015). Cancionero de los Ríos Pampeanos. Legislatura del gobierno de La Pampa.

Palacio, G, (2006). Breve guía de introducción a la Ecología Política (Ecopol): Orígenes, inspiradores, aportes y temas de actualidad. Bogotá: Revista Gestión y Ambiente, $9(3)$.

Raffestin, C. (1980). Por una Geografía del Poder. Traducción de Y. Velázquez, 2011. Michigan: Colegio de Michigan.

Scovenna, J. C. (2012). El caso del Río Atuel desde la perspectiva de los derechos humanos. Buenos Aires: Edición Pitanguá.

Souza M. J. Lopes de. (1995) O territorio: sobre espaco e poder, autonomía e desenvolvimento. En: Castro, I.; Gomes, P. y Correa, R. Rio de Janeiro: Geografía: conceitos e temas.

Ugalde, S. (2018). Nostalgias de un río. La Pampa.

Ulloa, A.; Romero Toledo, H. (eds.). (2018). Agua y disputas territoriales en Chile y Colombia. Bogotá: Universidad Nacional de Colombia, Facultad de Ciencias Humanas, Dpto. Geografía. 
Universidad Nacional de La Pampa (2012). Estudio para la cuantificación monetaria del daño causado a la provincia de La Pampa por la carencia de un caudal fluvioecológico del Río Atuel. Marcelo Gaviño Novillo (editor).

Wagner, L. (2019). Agricultura, cultura del oasis y megaminería en Mendoza. Debates y disputas. La Plata: Mundo agrario, 20(43). 